\title{
Numerical simulation of dispersion of ammonia in industry space using the ANSYS
}

\author{
Zdzisław Salamonowicz ${ }^{1, *}$ \\ ${ }^{1}$ The Main School of Fire Service, Faculty of Fire Safety Engineering, 52/54 Slowackiego St., 01-629 \\ Warsaw, Poland
}

\begin{abstract}
The article presents issues related to numerical simulations of the spread of dangerous substances in the air after emergency release from industrial installation. The work contains the results of numerical simulations of dispersion of ammonia and chlorine after emergency release made by using the ANSYS program, validated based on commonly used models: Gauss and heavy gas. Validation of experimental results based on research and empirical models allowed the selection of boundary parameters and the implementation of dispersion modelling in 3-d space taking into account technical infrastructure. Existing empirical models include terrain obstacles in the form of average roughness parameter, which is shown in general by the range of the danger zone without local topographic conditions. The numerical approach to modelling, in contrast to empirical models, allows to more accurately show the physicochemical phenomena occurring after release in 3-d space, both in the area around the chemical equipment and the buildings along the dangerous substance cloud.
\end{abstract}

\section{Introduction}

The dispersion of gases in the open space is a difficult issue to predict. In real conditions, the spread of gas is conditioned by a number of factors that affect to a greater or lesser extent the shape of the gas cloud, its speed of movement and inversion [1-7]. These factors are atmospheric conditions, temperature, wind speed, pressure, cloudiness or atmospheric precipitation [8-12]. In addition to atmospheric factors, an important role in the movement of the gas cloud is the terrain, that is, buildings, corrugations, spatial coverage [13-18]. An important atmospheric factor due to the dynamics of changes is the speed and direction of the wind [19-24]. With regard to chemical failure with short-range transport, measurements of meteorological stations can be used and the vertical wind profile can be determined taking also into account the atmosphere stability class [25-29]. To reduce the risk caused by a real chemical failure and dynamic changes of atmospheric factors, the probable physicochemical process is simulated using numerical calculation models based on real events and considering substance properties and boundary conditions based on modelled geometrical structures [30-36].

\footnotetext{
* Corresponding author: zsalamonowicz@sgsp.edu.pl
} 


\section{Material and methods}

In the research section, a numerical simulation of ammonia release from a pressure vessel was carried out. The simulation process was carried out using the ANSYS 14.5 environment, concentrating all the solvers offered by the program [37-41]. For the needs of the study geometry was created from scratch and includes a hypothetical plant with administration, production buildings and three pressure vessels with a volume of $2,400 \mathrm{~m}^{3}$ each (Fig. 1).

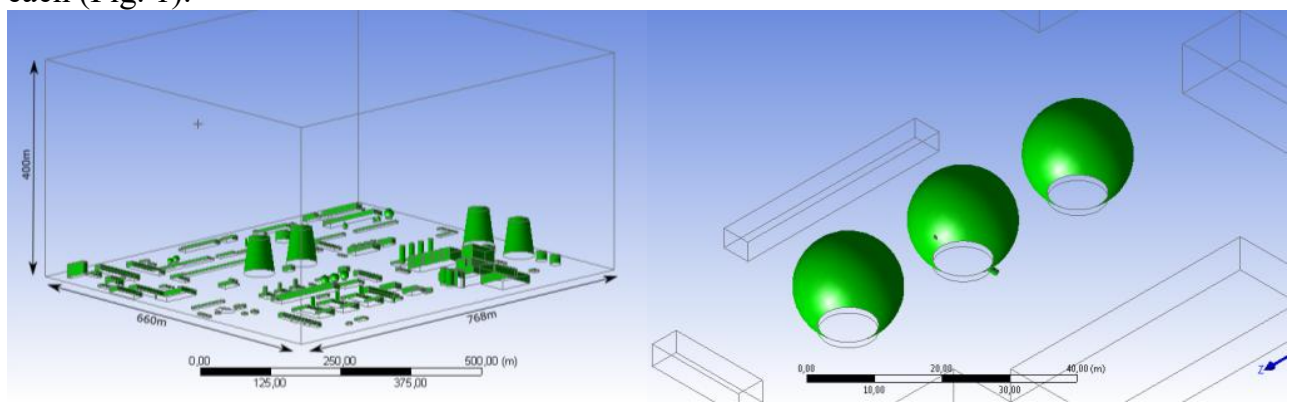

Fig. 1. Designed geometry of industrial space with pressure vessels.

Ansys Meshing was used to develop the grid [42-45]. After analyzing the effect of mesh density on the results, a numerical grid consisting of over 18 million tetrahedral elements was finally generated. In the local grid settings at the vessel within a radius of $8 \mathrm{~m}$, the element size was determined to be $0.1 \mathrm{~m}$, and the maximum element size was set to $50 \mathrm{~m}$. The numerical simulation of ammonia release was carried out in the Ansys Fluent software. In numerical modelling the RANS (Reynolds Averaged Navier-Stokes) method was used with the $\mathrm{k}-\varepsilon$ turbulence model in the standard version [46-48]. The RANS method is based on the introduction of time averaging into the Navier-Stokes motion equations [11-27, 2930, 32].

For the developed geometric model, the outflow of gaseous ammonia was simulated. All simulation scenarios are presented in table number 1 . The following wind velocities were introduced: $1,2,3 \mathrm{~m} / \mathrm{s}, 10 \mathrm{~kg} / \mathrm{s}$ outflow was used for different wind speeds. The flow direction was also changed to see how the environment affects the gas dispersion. The last variable parameter was the change in the amount of outflow of the substance. The outflow of various mass flow values for a leak was simulated to determine how the change in the parameter would affect the spread of the ammonia cloud. At the same wind speed, outflows of $3,2,1 \mathrm{~kg} / \mathrm{s}$ were simulated.

Table 1. List of modelled scenarios.

\begin{tabular}{|c|c|c|c|}
\hline No of simulation & Wind direction & Wind velocity $\mathrm{m} / \mathrm{s}$ & Emission kg/s \\
\hline 1 & \multirow{3}{*}{ west } & 1 & \multirow{3}{*}{10} \\
\hline 2 & & 2 & \\
\hline 3 & & 3 & \\
\hline 4 & \multirow{3}{*}{ east } & 1 & \multirow{3}{*}{10} \\
\hline 5 & & 2 & \\
\hline 6 & & 3 & \\
\hline 7 & \multirow{3}{*}{ south } & \multirow{3}{*}{1} & 3 \\
\hline 8 & & & 2 \\
\hline 9 & & & 1 \\
\hline
\end{tabular}


The results were presented in a graphical form using contour maps on specific surfaces and using iso-surface. To show the results, range markings, specific threshold concentrations were used in the program as a volume fraction: the threshold of detection $5 \mathrm{ppm}$ (0.000005), the value of ERPG-2 $150 \mathrm{ppm}$ (0.00015), mortality limit $1000 \mathrm{ppm}$ (0.001).

\section{Results}

Figures 2 and 3 present the range of threshold concentrations on the surface of the earth and on the whole surface of buildings in the isometric view, for the western direction of the wind. The results are presented in the form of contour maps, where the limit of detection is the threshold of perceptibility. The red outline determines the mortality limit.

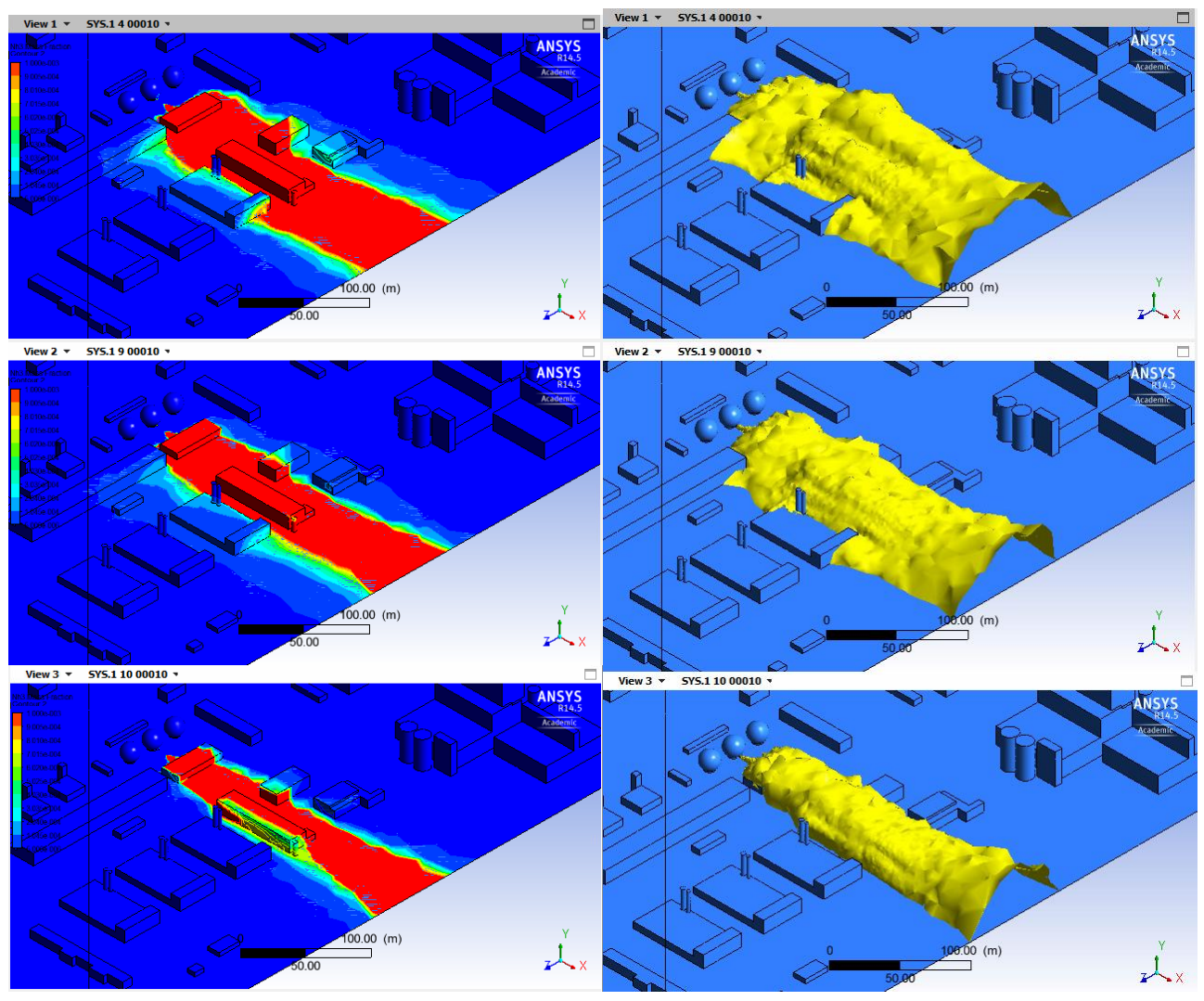

Fig. 2. Distribution of ammonia and ERPG-2 iso-surface for simulation 1 (top) - 3 (bottom).

Analysis of graphical results indicates that with the increase of wind speed, the width of the cloud decreases. Limitation of spreading by buildings located in the wind direction is visible. At a wind speed of $1 \mathrm{~m} / \mathrm{s}$, the cloud spreads perpendicular to the direction of the wind sideways, also behind obstacles. At a wind speed of $3 \mathrm{~m} / \mathrm{s}$, ammonia is torn away in the simplest way, and the space containing deadly concentration narrows considerably. The change in the size of the cloud clearly presents the surface area for the concentration of ERPG-2.

Figures 4 and 5 show a significant increase in the space occupied by the ammonia cloud compared to previous simulations. The range of the danger zone is significantly reduced 
already for a wind of $2 \mathrm{~m} / \mathrm{s}$. This suggests that the place of outflow of the substance along with certain atmospheric conditions can radically change the mode of dispersion of ammonia. For the narrowing of the ammonia cloud, for higher wind speeds, the chimneys of the cold water tanks, located so that the gas flows between them, are affected. At lower wind speeds, they cause a large swirl of the ammonia cloud that spreads quite quickly perpendicular to the direction of the wind. The range of deadly concentration at the end of the research area is three times greater for wind $1 \mathrm{~m} / \mathrm{s}$ compared to wind $3 \mathrm{~m} / \mathrm{s}$. At a wind speed of $3 \mathrm{~m} / \mathrm{s}$, the effect of generating a vacuum behind the building is also noticeable, which causes high ammonia suction and increases the concentration in the whole space behind the last building of the tested geometry. The influence of wind speed on the accidental lifting of the ammonia cloud is also noticeable. At low wind speeds, the ammonia cloud dominates, and at higher wind speeds it becomes the predominant factor.

Analyzing the results of the simulations presented in Figures 6 and 7, it can be concluded that the change in the ammonia emission volume proportionally increases the space of the cloud and its spreading range. The terrain obstacles are noticeable and the initial phase of outflow will take place. You can see a slight increase in the amount of the cloud in proportion to the increase in the value of the issue.
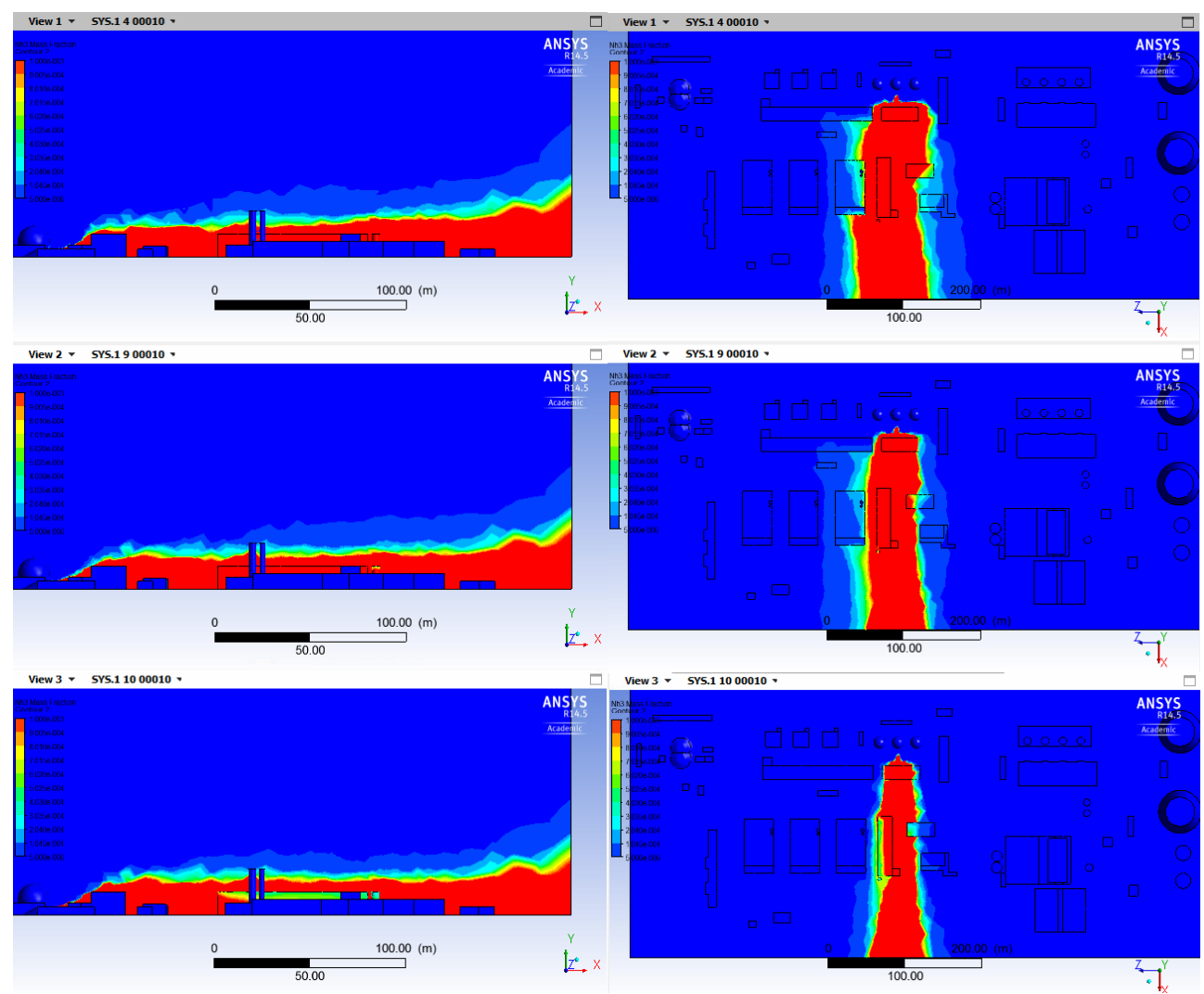

Fig. 3. Distribution of ammonia (concentrations) on a vertical surface consistent with the wind direction and source of emission and horizontal surface of the ground for simulation 1 (top) - 3 (bottom). 


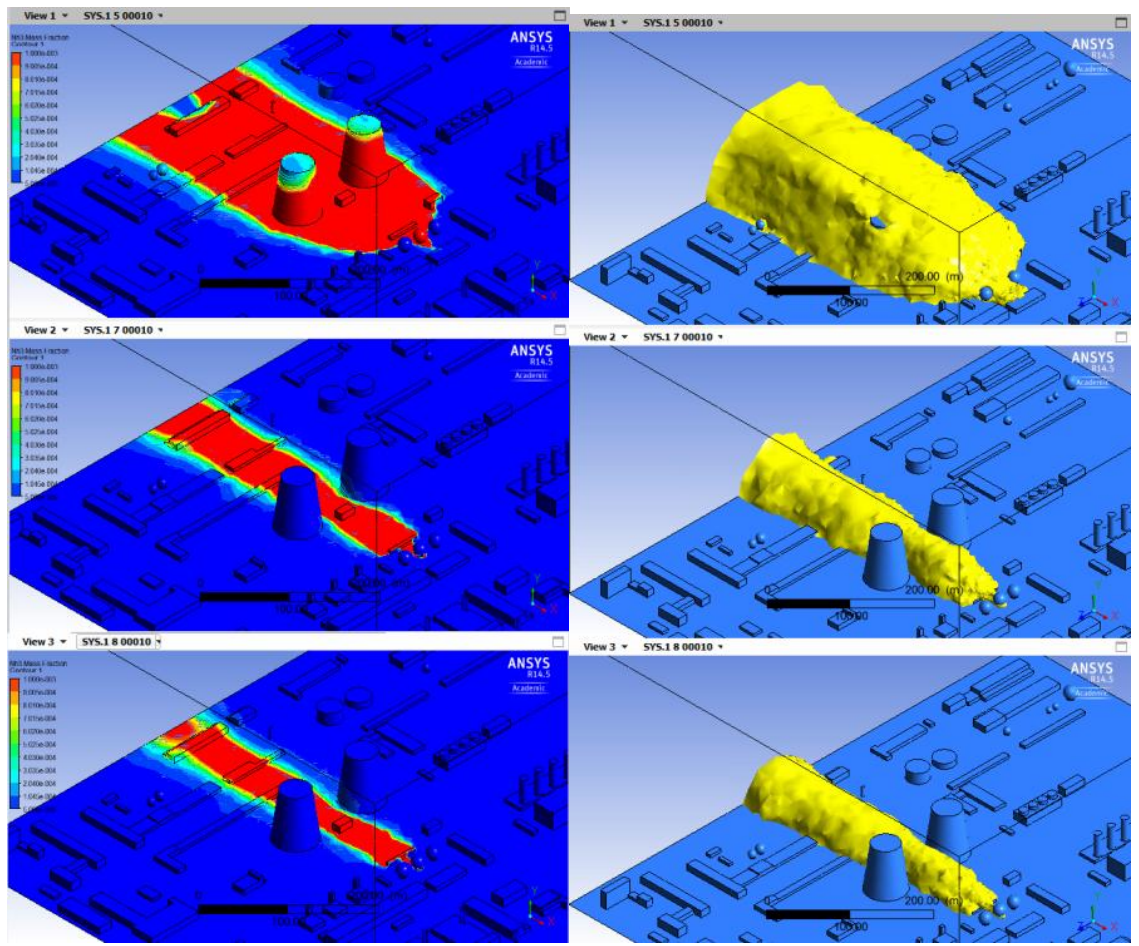

Fig. 4. Distribution of ammonia and ERPG-2 iso-surface for simulation 4 (top) - 6 (bottom).
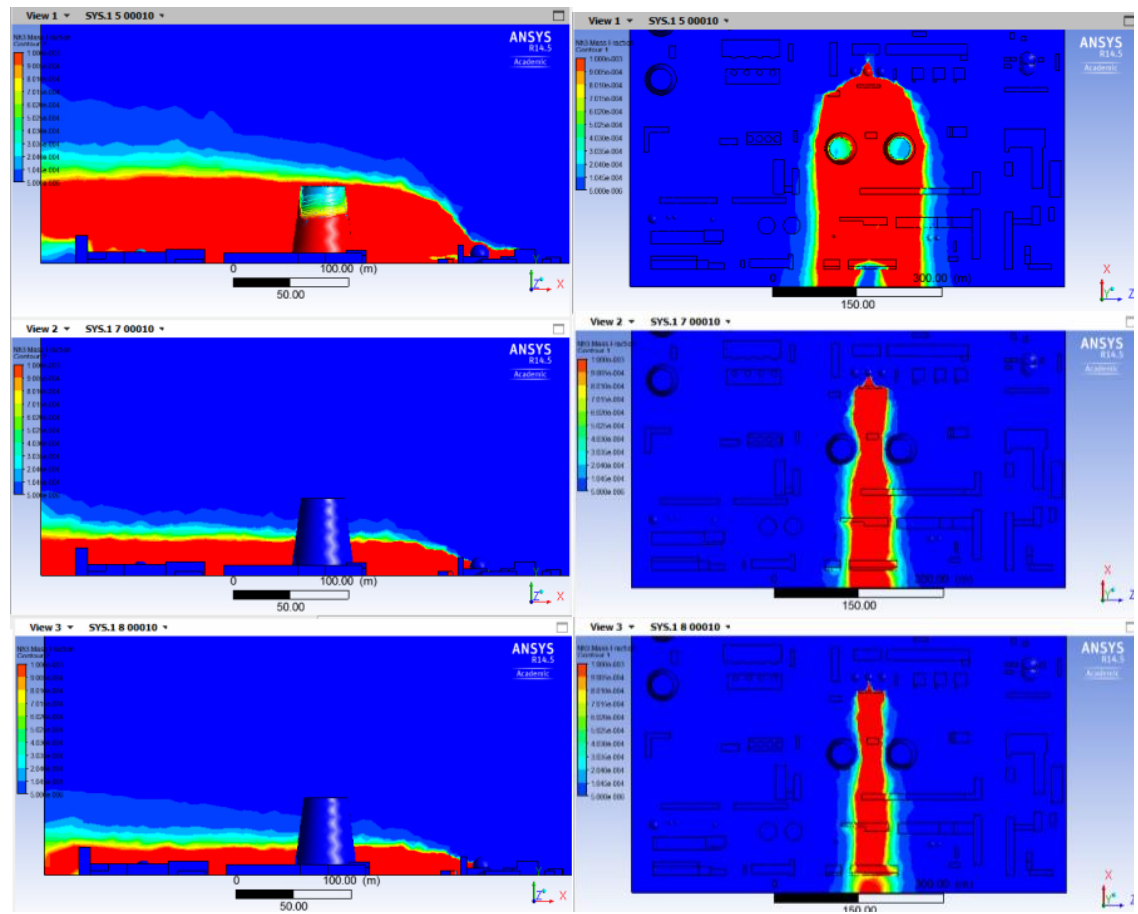

Fig. 5. Distribution of ammonia (concentrations) on the vertical surface in accordance with the wind direction and the source of emission and the horizontal surface of the soil for simulation 4 (top) - 6 (bottom). 

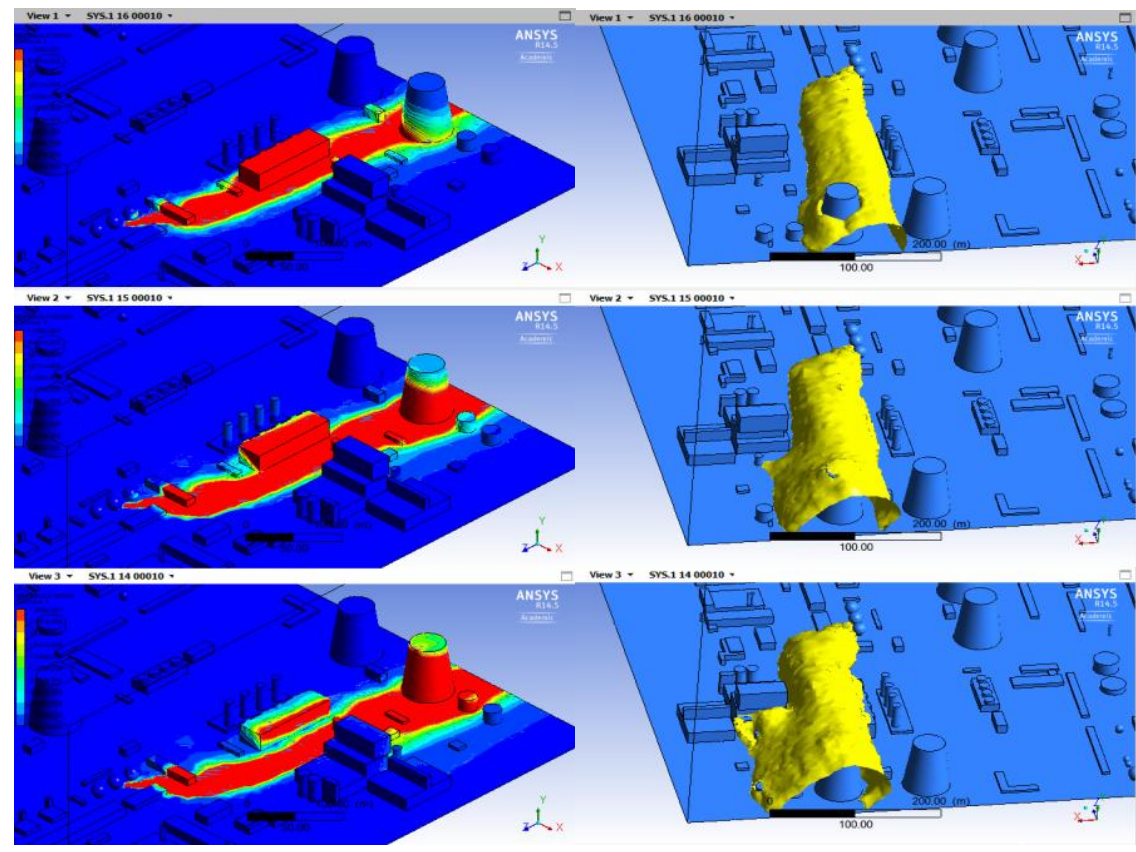

Fig. 6. Distribution of ammonia and ERPG-2 iso-surface for simulation 7 (top) - 9 (bottom).
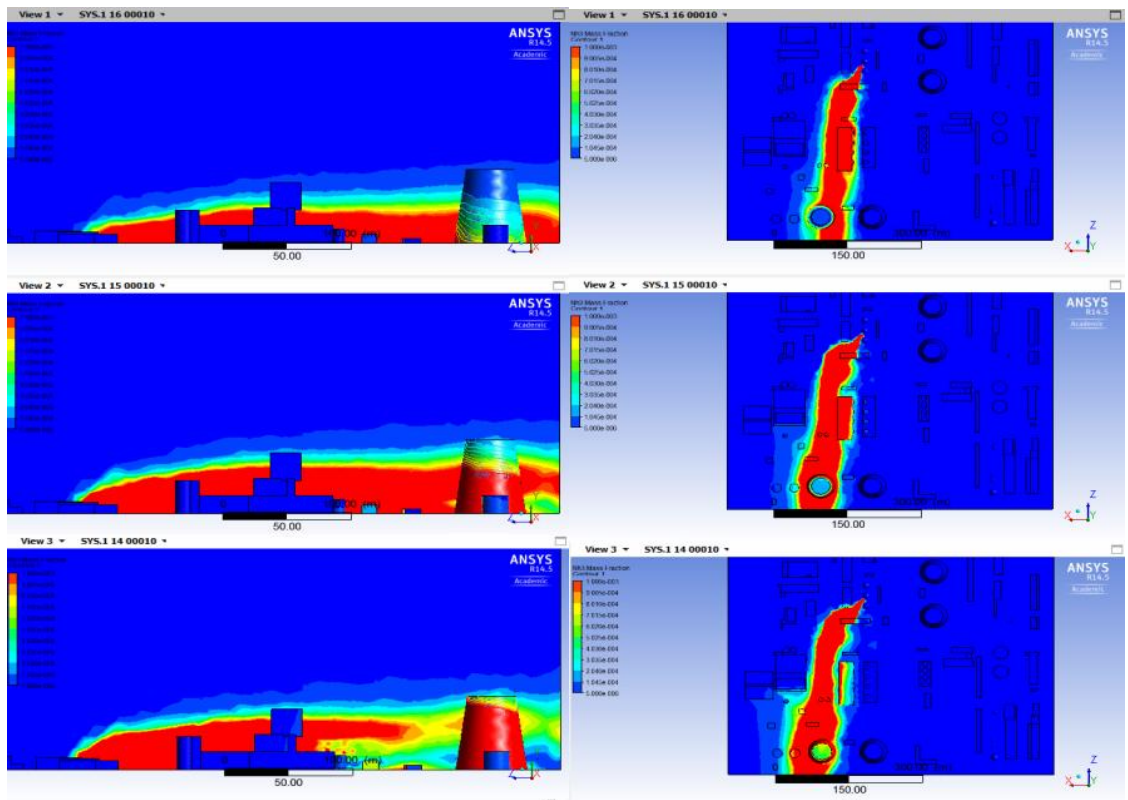

Fig. 7. Distribution of ammonia (concentrations) on a vertical surface in accordance with the wind direction and the source of emission and the horizontal surface of the soil for simulation 7 (top) - 9 (bottom).

\section{Conclusions}

Numerical analysis of ammonia dispersion in the industrial space allows taking into account the topographic condition of the terrain and more accurately replicates the cloud of 
toxic gas in space than simple 2D models. Illustrating the cloud in $3 \mathrm{D}$ space reveals the movement of ammonia along with the distribution of concentration. Taking into account the complex geometry of the industrial space and simulation of the toxic gas dispersion in it, it allows you to visualize the places where gas is stored, lift it, and move between individual facilities of the industrial infrastructure.

The accuracy of the solution is related to the high computing power of computers, however, access to computing clusters is more and more common and is no longer a challenge as it was a few years ago. Time to obtain results under the developed boundary conditions does not exceed a few hours on an average-sized workstation, and in the case of access to a computing cluster, it shortens to several minutes.

The simulations presented in the article depict the spread of ammonia after emergency release from the pressure vessel. The results include dispersion simulations for different directions and wind speed as well as ammonia emission values, in which the investment project for the construction of production and storage buildings in which hazardous substances will be used is included. The obtained results may in the future be used as data shaping spatial development plans.

\section{References}

1. P. Jamińska, Build. Environ., 10 (2012)

2. A. Polanczyk, Z. Salamonowicz, E3S Web of Conferences, 44, 8 (2018)

3. D. Dmochowski, A. Dmochowska, S. Biedugnis, ROS, 17 (2015)

4. A. Polanczyk, M. Podyma, L. Stefanczyk, I. Zbicinski, Chem. Eng. Process, 33, 9 (2012)

5. T. Wesierski, M. Majder-Lopatka, R. Matuszkiewicz, R. Porowski, Przem. Chem., 91, 3 (2012)

6. A. Piechota-Polanczyk, A. Goraca, Pharmacol. Rep., 64 (2012)

7. B. Blocken, T. van Hoff, Build. Environ., 61 (2013)

8. A. Piechota, A. Polanczyk, A. Goraca, Pharmacol. Rep., 63 (2011)

9. T. Wesierski, M. Majder-Lopatka, W. Wasik, Przem. Chem., 96, 5 (2017)

10. M. Majder-Lopatka, W. Rogula-Kozlowska, W. Wasik, E3S Web of Conferences, 44 (2018)

11. A. Piechota, A. Polanczyk, A. Goraca, Pharmacol. Rep., 62 (2010)

12. M. Majder-Lopatka, T. Wesierski, E3S Web of Conferences, 46 (2018)

13. M. Majder-Lopatka, T. Wesierski, W. Wasik, BiTP, 42, 8 (2016)

14. A. Piechota-Polanczyk, A. Jozkowicz, Curr. Drug Targets, 17 (2016)

15. A. Polanczyk, M. Podgorski, M. Polanczyk, N. Veshkina, I. Zbicinski, L. Stefanczyk, C. Neumayer, Interact. Cardiovasc. Thorac. Surg. (2018)

16. A. Polanczyk, P. Wawrzyniak, I. Zbicinski, Drying Technol., 31, 10 (2013)

17. P. Wawrzyniak, A. Polanczyk, I. Zbicinski, M. Jaskulski, M. Podyma, J. Rabaeva, Drying Technol., 30, 10 (2012)

18. Z. Salamonowicz, R. Makowski, E3S Web of Conferences, 44 (2018)

19. P. Wawrzyniak, M. Podyma, I. Zbicinski, Z. Bartczak, A. Polanczyk, J. Rabaeva, Drying Technol., 30, 9 (2012)

20. A. Piechota, A. Goraca, J. Physiol. Pharmacol. 62 (2011)

21. Z. Salamonowicz, M. Kotowski, M. Polka, W. Barnat, Bull. Pol. Ac.: Tech., 63 (2015)

22. W. Jarosz, Z. Salamonowicz, M. Majder-Lopatka, R. Matuszkiewicz, A. Dmochowska, Przem. Chem., 93 (2014)

23. A.D. Galeev, S.I. Ponikarov, E.V. Starovoytova, Process Saf. Environ., 91 (2013)

24. M. Polka, Z. Salamonowicz, M. Wolinski, B. Kukfisz, Procedia Eng., 45 (2012) 
25. A. Polanczyk, M. Podyma, L. Stefanczyk, W. Szubert, I. Zbicinski, J. Biomech., 48 (2015)

26. W. Eilenberg, S. Stojkovic, A. Piechota-Polanczyk, C. Kaun, S. Rauscher, M. Groger, M. Klinger, J. Wojta, C. Neumayer, I. Huk, S. Demyanets, Eur. J. Vasc. Endovasc. Surg., 51 (2016)

27. H. Zatorski, M. Salaga, M. Zielinska, A. Piechota-Polanczyk, K. Owczarek, R. Kordek, U. Lewandowska, C. Chen, J. Fichna, Naunyn Schmiedeberg's Arch. Pharmacol., 388 (2015)

28. A. Polanczyk, M. Strzelecki, T. Wozniak, W. Szubert, L. Stefanczyk, Foundations of Computing and Decision Sciences, 42, 13 (2017)

29. D. Dmochowski, A. Dmochowska, S. Biedugnis, ROS 17 (2015)

30. A. Piechota-Polanczyk, M. Zielinska, D. Piekielny, J. Fichna, Biomed. Pharmacother., 84 (2016)

31. A. Polanczyk, A. Piechota-Polanczyk, C. Domenig, J. Nanobachvili, I. Huk, C. Neumayer, Appl. Sci., 8, 14 (2018)

32. A. Polanczyk, M. Klinger, J. Nonobachvili, I. Huk, C. Neumayer, Appl. Sci., 8, 12 (2018)

33. A. Polanczy, T. Wozniak, M. Strzelecki, W. Szubert, L. stefanczyk, Signal Processing SPA 5 (2016)

34. A. Zieminska-Stolarska, A. Polanczyk, I. Zbicinski, J. Hydrol. Hydromech., 644, 8 (2015)

35. Z. Salamonowicz, W. Jarosz, BiTP, 3 (2012)

36. M. Wlodarczyk, A. Sobolewska-Wlodarczyk, A. I. Cygankiewicz, D. Jacenik, A. Piechota-Polanczyk, K. Stec-Michalska, W. M. Krajewska, J. Fichna, M. WisniewskaJarosinska, J. Gastrointestin. Liver Dis., 26 (2017)

37. M. Salaga, L. V. Blomster, A. Piechota-Polanczyk, M. Zielinska, D. Jacenik, A. I. Cygankiewicz, W. M. Krajewska, J. D. Mikkelsen, J. Fichna, J. Pharmacol. Exp. Ther., 356 (2016)

38. A. Piechota-Polanczyk, S. Demyanets, O. Nykonenko, I. Huk, M. Mittlboeck, C. M. Domenig, C. Neumayer, J. Wojta, J. Nanobachvili, M. Klinger, Eur. J. Vasc. Endovasc. Surg., 45 (2013)

39. A. Polanczyk, A. Piechota-Polanczyk, L. Stefanczyk, PlosOne, 12 (2017)

40. A. Polanczyk, M. Podyma, L. Trebinski, J. Chrzastek, I. Zbicinski, L. Stefanczyk, PLoS One, 11 (2016)

41. M. Salaga, U. Lewandowska, D. Sosnowska, P. K. Zakrzewski, A. I. Cygankiewicz, A. Piechota-Polanczyk, M. Sobczak, P. Mosinska, C. Chen, W. M. Krajewska, J. Fichna, Naunyn Schmiedeberg's Arch. Pharmacol., 387 (2014)

42. A. Piechota-Polanczyk, M. Wlodarczyk, A. Sobolewska-Wlodarczyk, M. Jonakowski, A. Pilarczyk, K. Stec-Michalska, M. Wisniewska-Jarosinska, J. Fichna, Dig. Dis. Sci., 62 (2017)

43. Z. Salamonowicz, M. Kotowski, M. Polka, W. Barnat, Przem. Chem., 93 (2014)

44. Z. Salamonowicz, M. Wolinski, M. Sobolewski, M. Polka, Przem. Chem., 93 (2014)

45. Z. Salamonowicz, M. Majder-Lopatka, BiTP, 30 (2013)

46. A. Dmochowska. Wars. Univ. Tech. Pub. (2009)

47. A. Piechota-Polanczyk, A. Kopacz, D. Kloska, B. Zagrapan, C. Neumayer, A. Grochot-Przeczek, I. Huk, C. Brostjan, J. Dulak, A. Jozkowicz, Oxid. Med. Cell Longev., 2018 (2018)

48. A. Polanczyk, M. Podgorski, T. Wozniak, L. Stefanczyk, M Strzelecki, Medicina, 54, 15 (2018) 